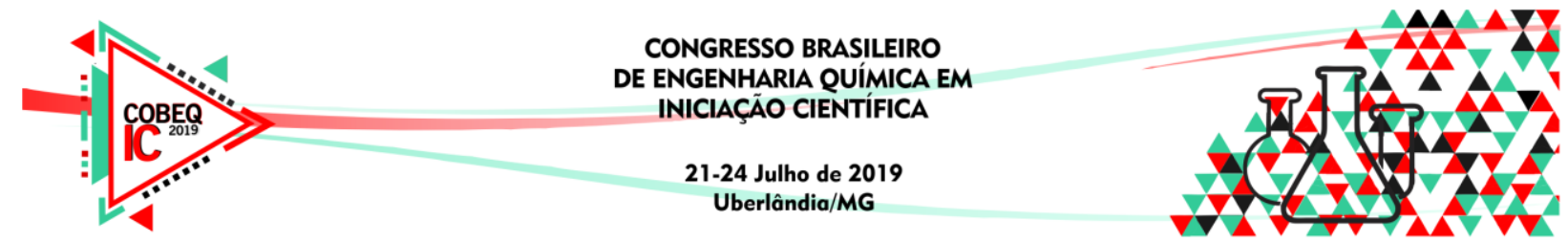

\title{
ESTUDO, SIMULAÇÃO E ANÁLISE DO EFEITO DA TEMPERATURA NO RENDIMENTO DA FERMENTAÇÃO PARA PRODUÇÃO DE ETANOL DE SEGUNDA GERAÇÃO
}

\author{
P.C ZANESCO ${ }^{1}$, A.B.R. JESUS ${ }^{1}$, W. C. SILVA $^{1}$, A. C. O. MAFRA ${ }^{1}$ \\ ${ }^{1}$ Universidade Federal de Mato Grosso, Faculdade de Engenharia de Várzea Grande \\ E-mail para contato: patrickzanesco@gmail.com
}

\begin{abstract}
RESUMO - O bioetanol da cana-de-açúcar tem se mostrado como a melhor alternativa aos combustíveis fósseis. No entanto, com o crescimento da escolha por este combustível, cresce também a produção do bagaço da cana-de-açúcar, que por vezes é deixado no campo para proteção do solo ou como material de queima para produção de energia nas caldeiras. Nesse contexto, muitos estudos estão sendo feitos no que tange melhorias para produção de etanol de segunda geração - uma possibilidade que exprime provável melhoria no uso deste rejeito. O presente trabalho objetivou estudo, simulação e análise do efeito da temperatura no rendimento da fermentação para produção de etanol de segunda geração a partir do bagaço da cana-de-açúcar. A partir dos perfis cinéticos foi possível analisar a interferência da temperatura no meio reacional.
\end{abstract}

\section{INTRODUÇÃO}

O crescimento da demanda de etanol de cana-de-açúcar tende a alcançar 67 milhões de metros cúbicos no ano de 2020, tendo em vista de que este combustível é uma das melhore alternativas aos combustíveis fósseis atualmente. Nesse sentido, a crescente utilização da cana como matéria prima tem como consequência o aumento em volume de bagaço da cana-deaçúcar, visto que são gerados $250 \mathrm{~kg}$ de bagaço de cana para cada tonelada da matéria prima processada (BETANCUR, 2010).

$\mathrm{O}$ uso do bagaço tem sido majoritariamente implementado em caldeiras como combustível de queima. No entanto, este uso está longe de ser o ideal, tanto pelo ponto de vista ambiental quanto pelo aproveitamento energético e econômico. Assim, muitos estudos visam a utilização deste rejeito para produção de etanol de segunda geração, visto que este ainda possui uma alta carga de açúcares presentes na biomassa lignocelulósica (AZEVEDO, 2009).

No processo de obtenção de etanol de segunda geração, o bagaço deve passar por alguns processos antes que se consiga fazer a extração dos açúcares incorporados como mostra na Figura 1. Após a extração do caldo da cana-de-açúcar, parte do bagaço é encaminhado como alimentação para as caldeiras, outra parte passa por um pré-tratamento, que pode se dar por uma rota física, química (ácida ou básica) - mais comumente usadas nas industrias ou físicoquímica, e posteriormente a celulose pode ser hidrolisada por uma rota ácida ou enzimática e por fim filtrada e fermentada obtendo o produto desejado. 


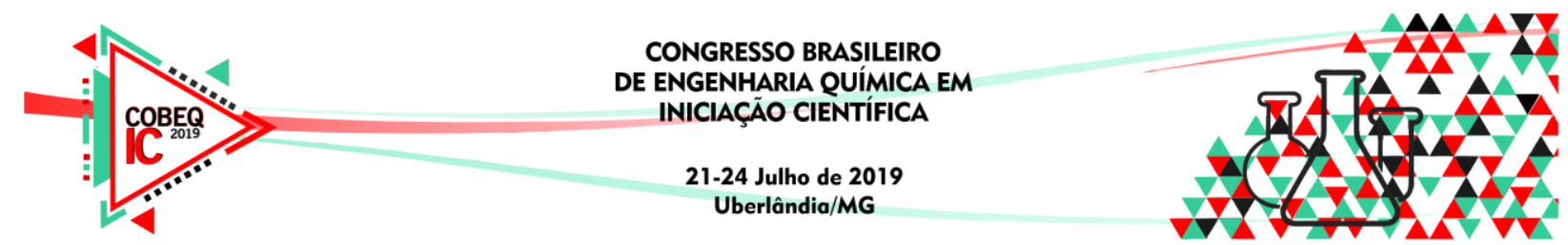

Figura 1 - Diagrama de blocos para o processo de produção de etanol de primeira e segunda geração a partir da cana de açúcar.

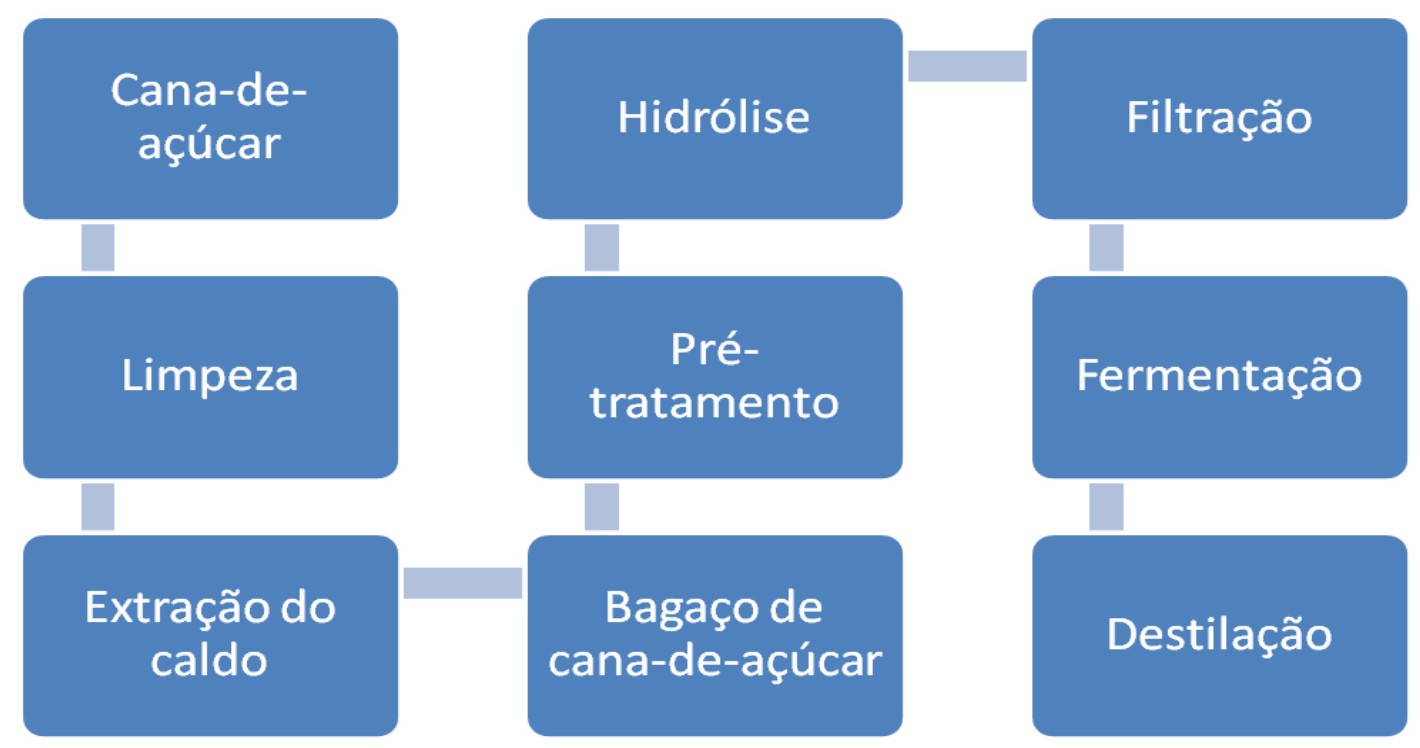

Um dos parâmetros mais importantes a ser considerado durante a fermentação é a temperatura. Com uma alta variação da temperatura no biorreator, podem acontecer diversos fenômenos como a degradação do produto a morte e inativação celular que podem acarretar numa queda da eficiência do processo (ANDRADE, 2012).

Para a avaliação da viabilidade econômica e ambiental da obtenção do etanol de segunda geração vê-se a necessidade de uma estrutura entre a modelagem e a simulação da cinética e a parte experimental, em vista que a aplicação prática é por vezes custosa, a modelagem e simulação das condições se tornam necessária com o intuito da economia de recursos financeiros e humanos (WOODLEY, 2019).

Tendo isso em vista, o presente estudo tem por objetivo a execução de um método de otimização de processos denominado como janela operacional. Para tanto, se faz necessária a simulação e análise da influência da temperatura nos modelos fermentativos para a produção do etanol de segunda geração a partir do bagaço de cana-de-açúcar com o auxílio do software de simulação de bioprocessos SimulaFerm do pacote computacional AnabioPlus. Para a análise dos parâmetros do biorreator e execução da janela operacional.

\section{MATERIAIS E MÉTODOS}

\subsection{Coleta de dados}

Para este caso de estudo foram considerados os parâmetros apresentados na Tabela 1 (ANDRADE, 2012) a partir de um pré-tratamento do bagaço da cana-de-açúcar utilizando 


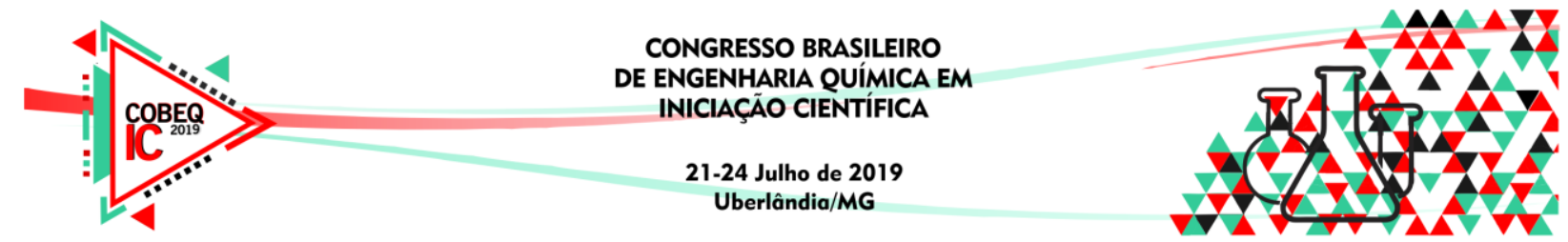

peróxido de hidrogênio $\left(\mathrm{H}_{2} \mathrm{O}_{2}\right)$ a uma concentração de $7.36 \%$ com pH ajustado a 11.5 usando hidróxido de sódio $(\mathrm{NaOH})$ e posteriormente ajustado o $\mathrm{pH}$ para $4.8 \mathrm{com}$ adição de citrato de sódio $\left(\mathrm{Na}_{3} \mathrm{C}_{6} \mathrm{H}_{5} \mathrm{O}_{7}\right)$, seguido de uma hidrólise enzimática em presença de $\beta$-glucosidase e celulase. A simulação da fermentação foi realizada com o micro-organismo Saccharomyces cerevisiae em um biorreator com volume operacional de 1 litro.

Tabela 1 - Parâmetros obtidos para cinética fermentativa para as temperaturas $30,32,34,36$ e $38\left({ }^{\circ} \mathrm{C}\right)$ (ANDRADE, 2012).

\begin{tabular}{|c|c|c|c|c|c|}
\hline Parâmetros & \multicolumn{5}{|c|}{ Temperaturas $\left({ }^{\circ} \mathrm{C}\right)$} \\
\hline \hline & 30 & 32 & 34 & 36 & 38 \\
\hline $\mathrm{S}(\mathrm{g} / \mathrm{L})$ & 149,464 & 141,263 & 150,628 & 149,325 & 147,701 \\
\hline $\mathrm{X}(\mathrm{g} / \mathrm{L})$ & 2,56 & 2,82 & 2,69 & 3,06 & 2,22 \\
\hline $\mathrm{P}_{\max }\left(\mathrm{kg} / \mathrm{m}^{3}\right)$ & 96,000 & 81,340 & 75,000 & 72,400 & 72,020 \\
\hline$\mu \max (1 / \mathrm{h})$ & 0,15 & 0,18 & 0,19 & 0,179 & 0,145 \\
\hline $\mathrm{Yp} / \mathrm{s}(\mathrm{kg} / \mathrm{kg})$ & 0,421 & 0,422 & 0,465 & 0,408 & 0,462 \\
\hline $\mathrm{Yx} / \mathrm{s}(\mathrm{kg} / \mathrm{kg})$ & 0,023 & 0,026 & 0,025 & 0,023 & 0,024 \\
\hline
\end{tabular}

\subsection{Simulação do perfil cinético}

A simulação do perfil cinético foi realizada com o auxílio do SimulaFerm - software computacional usado para simulação de bioprocessos a partir da determinação de alguns parâmetros.

Para a execução da simulação inicialmente deve-se definir a política de processo utilizada (batelada, batelada alimentada ou processo contínuo), depois disso se define a cinética de produção (associação do produto com o crescimento celular). Por fim se define o modelo de crescimento celular e introduz os parâmetros citados na Tabela 1.

Nesta simulação considerou-se que o processo em regime de batelada, com a cinética de produção associada ao crescimento e para o modelo de crescimento celular utilizou o modelo de Monod. Os coeficientes de morte celular e degradação do produto não foram considerados para confecção das curvas cinéticas.

\subsection{Análise da viabilidade econômica do processo}

A análise da viabilidade do processo se utilizou a metodologia aplicada por Tufvesson et al. (2013), que propõe três métricas que indicarão a viabilidade, para cada fermentação estudada: rendimento do inóculo $\left(\mathrm{Y}_{\mathrm{x} / \mathrm{s}} ; \mathrm{g}_{\text {produto. }} \mathrm{g}_{\text {celulas }}{ }^{-1}\right)$, concentração de produto ( $\mathrm{Cp}$; $\mathrm{g}_{\text {produto. }} \mathrm{L}^{-1}$ ) e o rendimento espaço-tempo (RET; g produto. $\mathrm{L}^{-1} \mathrm{~h}^{-1}$ ). Para o critério de avaliação foram utilizadas as condições mostradas na Tabela 2.

A partir da Tabela 2 o bioetanol pode ser considerado um produto de baixo custo (cerca de $0.6 € . \mathrm{Kg}^{-1}$ ), nesse caso o rendimento da reação deve ser maior que $99 \%$, com uma concentração de produto de 200-400 gramas de produto por litro em uma escala de mais de 25 metros cúbicos. A análise da produtividade foi feita a partir da limitação do intervalo de 


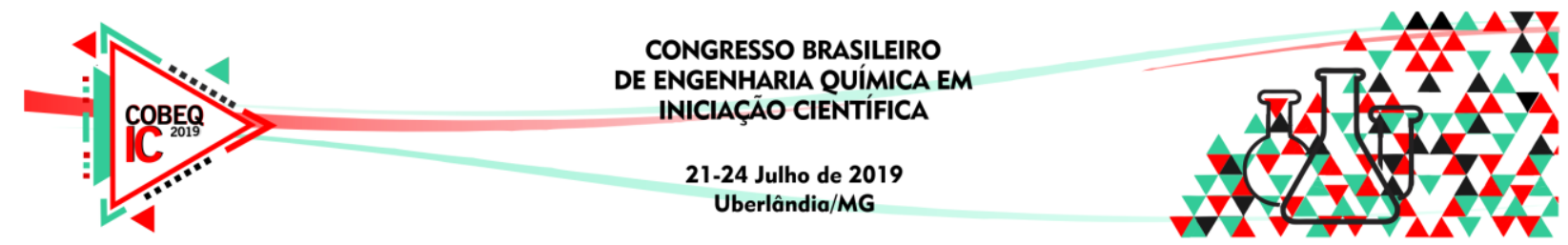

produção, e posteriormente a avaliação do rendimento de produto por espaço de reator em uma hora.

Tabela 2 - Parâmetros de referência definidos para aumento de escala de um processo biocatalítico em diferentes setores (TUFVESSON et al, 2013).

\begin{tabular}{|c|c|c|c|c|c|c|}
\hline Setores & Custo $\left(€ . \mathrm{kgP}^{-1}\right)$ & $\mathrm{Y}$ (gpr/gcat) & Yreação (\%) & $\mathrm{Cp}$ & RET & Escala \\
\hline $\begin{array}{l}\text { Química fina / } \\
\text { fármacos }\end{array}$ & $>100$ & $10-100$ (g/g.s) & Alto $(>80 \%)$ & $50-100$ & $>1.0$ & $0.1-10$ \\
\hline Especiarias & $10-50$ & $100-1000$ (g/g.s) & Alto $(>80 \%)$ & $100-200$ & $>2.5$ & $10 \sim 25$ \\
\hline $\begin{array}{l}\text { Produtos de } \\
\text { baixo custo }\end{array}$ & $0.5-10$ & $1000-10000$ (g/g.s) & Muito alto (>99\%) & $200-400$ & $>10$ & $>25$ \\
\hline
\end{tabular}

\section{RESULTADOS E DISCUSSÕES}

Aplicando os parâmetros cinéticos na interface do software AnabioPlus foi possível obter os perfis de consumo de substrato, crescimento celular, velocidade específica de crescimento celular, produtividade específica, produtividade das células e concentração de produto em função do tempo, para cada temperatura de estudo $\left(30-38{ }^{\circ} \mathrm{C}\right)$, como mostram nas Figuras 2 e 3 . A partir das análises feitas para cada situação foi possível perceber que a temperatura ótima para a fermentação nessas concentrações se deu à aproximadamente $34^{\circ} \mathrm{C}$, não só pela produção de 70 g. $\mathrm{L}^{-1}$ de etanol, mas pela sua superioridade na produtividade de produto por tempo (PCp) alcançando $2.5 \mathrm{~g} \cdot \mathrm{L}^{-1} \cdot \mathrm{h}^{-1} \mathrm{e}$ produtividade celular em função do tempo (PCx) alcançando $0.148 \mathrm{~g} . \mathrm{L}^{-1} \cdot \mathrm{h}^{-1}$.

Pode-se fazer também uma comparação de produtividade celular (PCx) entre as curvas das temperaturas de $36^{\circ} \mathrm{C}$, representada pela cor roxa, e $34^{\circ} \mathrm{C}$, azul. Percebe-se que por um período de tempo a produtividade celular em $36^{\circ} \mathrm{C}$ é maior, isso se dá pela quantidade de células presente. Conforme a tabela, a quantidade de inoculo em g. $\mathrm{L}^{-1}$ é consideravelmente maior no experimento da curva de $36^{\circ} \mathrm{C}$ que a curva da temperatura ótima $\left(34^{\circ} \mathrm{C}\right)$. No entanto, a curva de produtividade celular na temperatura ótima passa a possuir um maior rendimento devido sua maior velocidade específica máxima de crescimento celular ( $\mu$ max). Mesmo com sua máxima produtividade em $34{ }^{\circ} \mathrm{C}$, obtendo 96 gramas de produto por litro de reator, o processo não alcança os valores de parâmetros determinados pela Tabela 2.

\section{CONCLUSÃO}

Com base nos resultados obtidos, foi possível perceber a interferência da temperatura na cinética fermentativa do processo de obtenção de etanol a partir do bagaço de cana-de-açúcar. No entanto, a produtividade máxima obtida nas simulações não alcança os valores de referência para aumento de escala do processo. Para que seja possível uma maior produtividade, e os valores de produtividade alcance os desejados, os estudos futuros visam aplicar a simulação em uma política de processo de batelada alimentada com reciclo de células, para que se obtenha um maior rendimento de produto por quantidade de células. 
Figura 2 - Curvas de concentração de substrato, crescimento celular e velocidade específica de crescimento celular em função do tempo para as temperaturas $30,32,34,36$ e $38\left({ }^{\circ} \mathrm{C}\right)$.
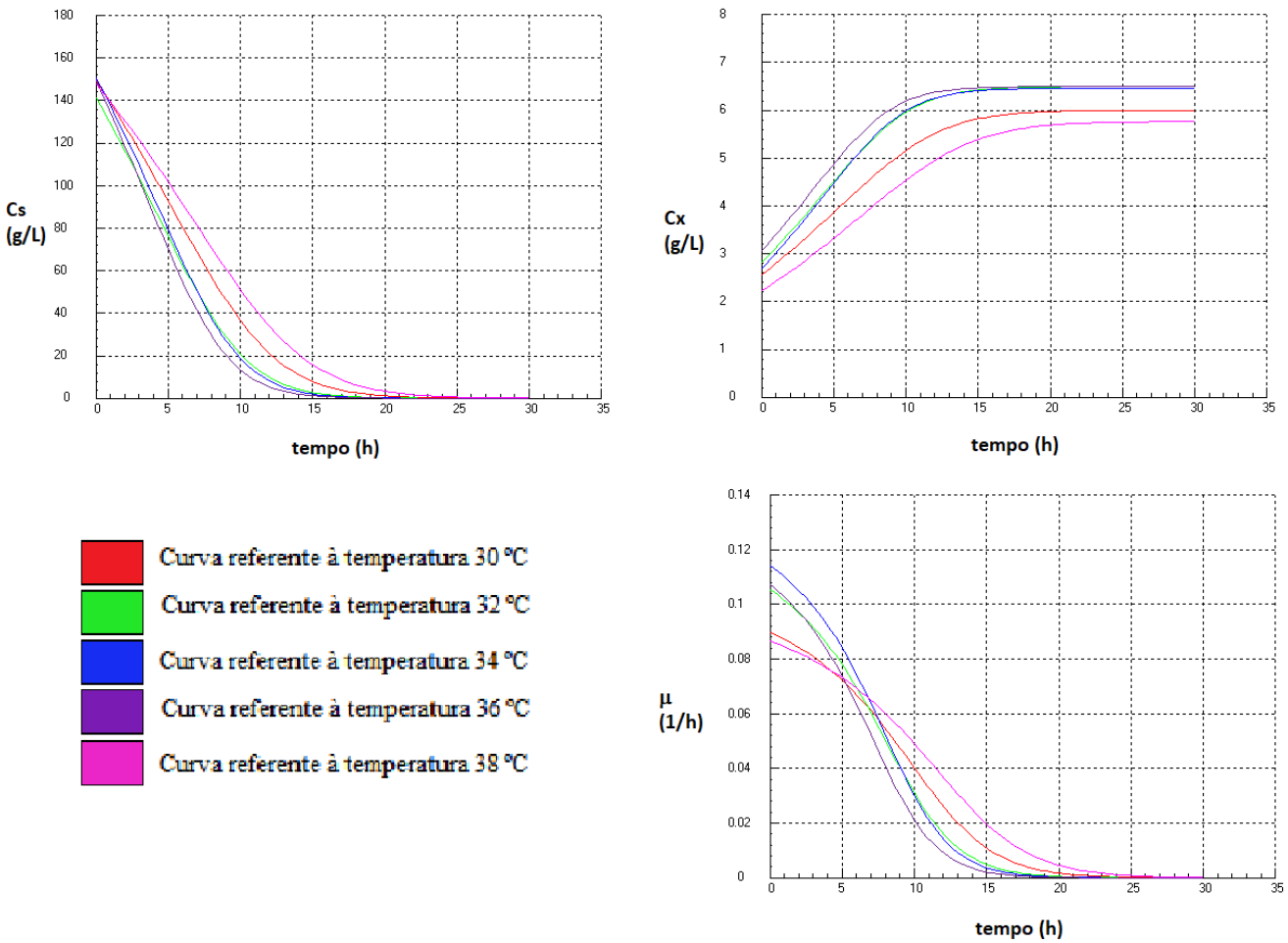

Figura 3 - Curvas de produtividade celular específica, formação de produto e produtividade do produto em função do tempo para as temperaturas $30,32,34,36$ e $38\left({ }^{\circ} \mathrm{C}\right)$.
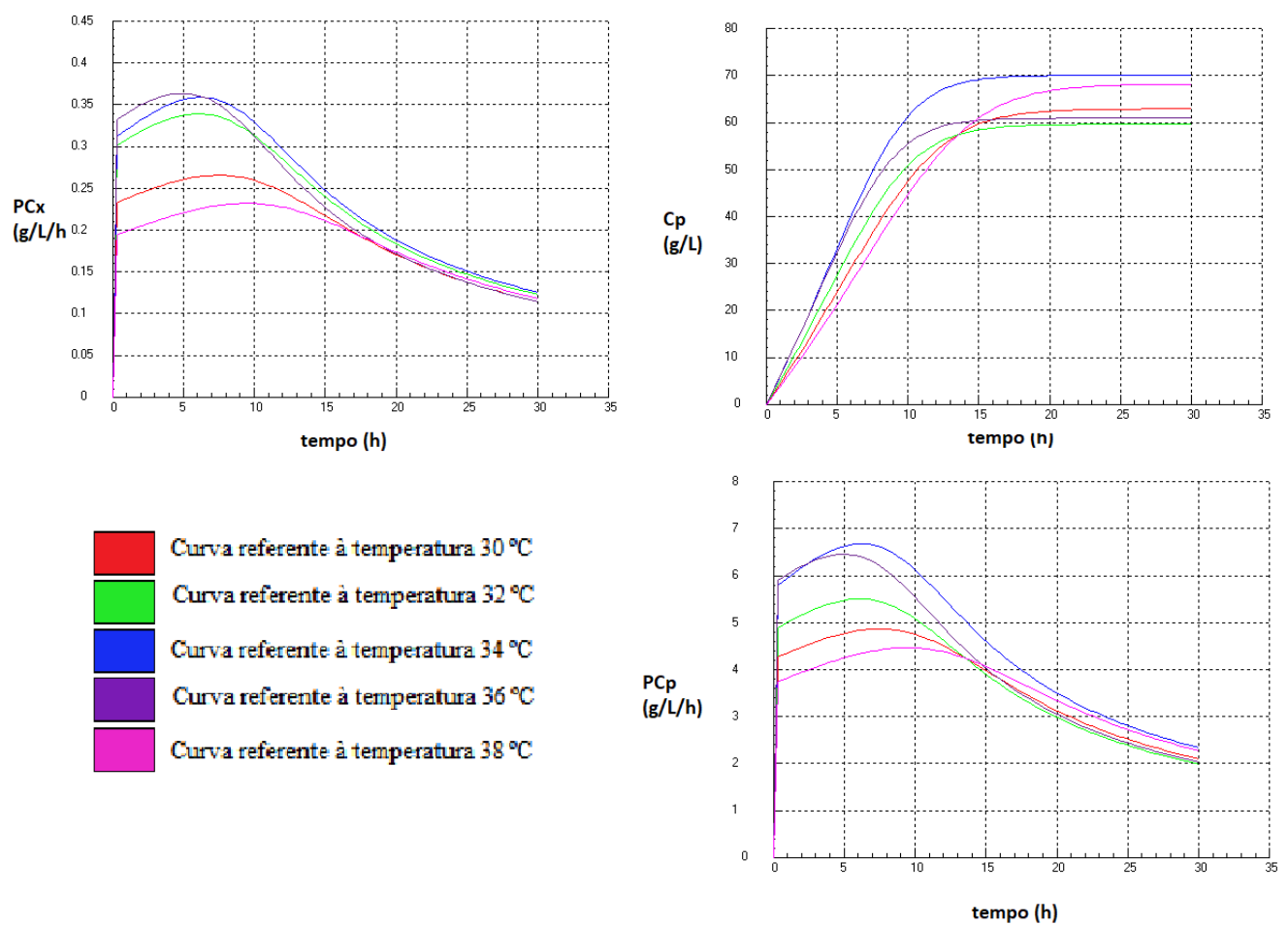


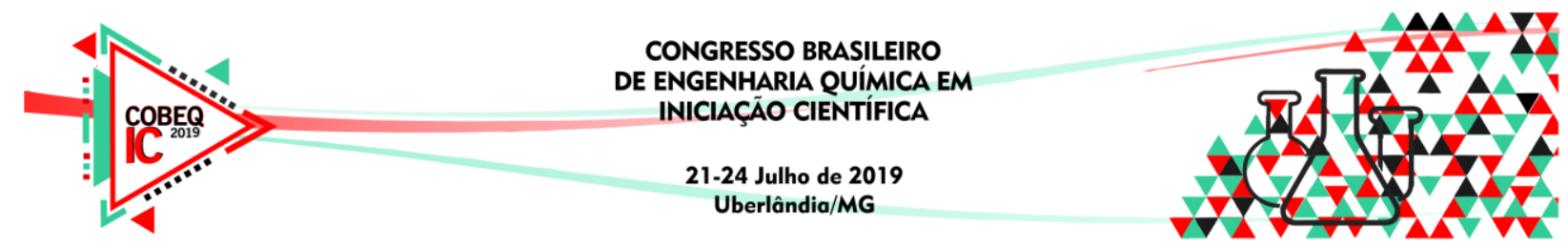

\section{NOMENCLATURA}

Cs - Concentração de substrato

$\mathrm{Cx}$ - Concentração de células

$\mu_{\max }$ - Velocidade específica máxima de crescimento celular

$\mathrm{Yp} / \mathrm{s}$ - Coeficiente de rendimento de substrato por produto

$\mathrm{Yx} / \mathrm{s}$ - Coeficiente de rendimento de substrato por produto

RET - Rendimento espaço-tempo

$\mathrm{Cp}$ - Concentração de produto

Yreação - Rendimento da reação

$\mathrm{Y}$ - Rendimento de produto por quantidade de células

\section{AGRADECIMENTOS}

Os autores agradecem à Faculdade de Engenharia de Várzea Grande - UFMT.

\section{REFERÊNCIAS}

ANDRADE, R. R.; MAUGERI FILHO, F.; MACIEL FILHO, R. Kinetics of ethanol production from sugarcane bagasse enzymatic hydrolysate concentrated with molasses under cell recycle. Bioresour. Technol., p. 351-359. 2012.

AZEVEDO, J. M.; GALIANA, F. D. The Sugarcane Ethanol Power Industry in Brazil: Obstacles, Success and Perspectives. Inst. Elect. Electr. Eng., p. 1-6. 2009.

BETANCUR, J. V.; PEREIRA JUNIOR, N. Sugar cane bagasse as feedstock for second generation ethanol production.: Part I: Diluted acid pretreatment optimization. Ele. J. of Biotech., p. 1-9. 2010.

DIAS, M. O. S.; CUNHA, M. P.; MACIEL FILHO, R. Simulation of integrated first and second generation bioethanol production from sugarcane: comparison between different biomass pretreatment methods. J. Ind Microbio Bioethanol., p. 955-966. 2010.

TUFVESSON, P.; LIMA-RAMOS, J. Advances in the process development of biocatalytic Process. Org Process Res Dev., p. 1-6. 2013.

WOODLEY, J. M.; RUALES-SALCEDO, A. V.; HIGUITA, J. C. Design of enzymatic cascade processes for the production of low-priced chemicals. Z. Naturforsch, p. 1-8. 2019. 